\title{
PELAKSANAAN PEMBERIAN HAK-HAK NARAPIDANA PELAKU TINDAK PIDANA PEMBUNUHAN (STUDI DI LEMBAGA PEMASYARAKATAN KLAS II B GUNUNGSITOLI, NIAS)
}

\author{
Oleh: \\ Fadil Selamat Harefa ${ }^{1)}$ \\ Kurnia Konstan Telaumbanua ${ }^{2)}$ \\ Universitas Darma Agung, Medan., ${ }^{1,2}$ \\ E-mail: \\ fadilharefa1995@gmail.com ${ }^{1)}$, \\ Telaumbanuaconstan9@gmail.com ${ }^{2)}$
}

\begin{abstract}
This study aims at finding how the implementation of the granting of rights for murder convicts in Gunung Sitoli Class II B Prison, Nias and the training process at the Gunung Sitoli Class II B Penitentiary, Nias towards murder convicts.

Penitentiary as the last place of the criminal correctional system, its task is to carry out the development of prisoners. In carrying out the development of prisoners, the correctional institution is guided by the provisions of Law Number 12 of 1995 concerning Corrections. Prisoners are not people who are excommunicated for actions committed as a result of violating the law. The law regulates the rights of prisoners. The formulation of the problem in this journal is how the implementation of the granting of rights and how the process of coaching the prisoner is. The method used is juridical empirical or juridical empirical research where the legal materials used are primary legal materials, secondary legal materials and tertiary legal materials. The results of the study concluded that the implementation of granting rights to murder convicts in Gunungsitoli Class II B Penitentiary, Nias was carried out in accordance with the Law. The coaching process starts when the prisoner is detained at the Police, then at the Gunungsitoli Detention Center at the stage of undergoing a trial and continues at the Class II B Prison in Gunung Sitoli, Nias until the prisoner is released.
\end{abstract}

Keywords: Prisoners' Rights, Murder

Lembaga Pemasyarakatan sebagai tempat terakhir dari sistem pemasyarakatan pidana,tugasnya adalah melaksanakan pembinaan narapidana. Di dalam melaksanakan pembinaan narapidana, Lembaga Pemasyarakatan berpedoman kepada ketentuanUndangUndangNomor 12 Tahun 1995 Tentang Pemasyarakatan. Narapidana bukanlah orang yang dikucilkan atas perbuatan yang dilakukan akibat melanggar hukum. Di dalam UndangUndang tersebut telah mengatur hak-hak narapidana. Adapun rumusan masalah dalam jurnal ini yaitu bagaimanakah pelaksanaan pemberian hak-hak dan bagaimanakah proses pembinaann Narapidana tersebut. Metode yang digunakan yaitu yuridis empiris atau penelitian yuridis empiris yang bahan hukum yang digunakan adalah bahan hukum primer, bahan hukum sekunder dan bahan hukum tersier. Hasil penelitian disimpulkan bahwa pelaksanaan pemberian hak-hak narapidana pelaku tindak pidana pembunuhan di Lembaga Pemasyarakatan Klas II B Gunungsitoli, Nias telah dilaksanakan sesuai dengan UndangUndang. Adapun proses pembinaannya yaitu dimulai pada saat narapidana tersebut ditahan di Kepolisian yang selanjutnya di Rutan Gunungsitoli pada tahap sedang menjalani persidangan dan di lanjutkan di Lembaga Pemasyarakatan Klas II B Gunung Sitoli, Nias sampai narapidana tersebut bebas.

Kata Kunci : Hak-hak narapidana, pembunuhan 


\section{PENDAHULUAN}

\section{A. Latar Belakang}

Manusia adalah makluk makhluk sosial yang tidak akan pernah dapat dipisahkan dari masyarakat. Untuk itu manusia membuat norma atau aturan yang berguna dalam melakukan hubungan-hubungan kemasyarakatan agar tidak terjadi kekacauan. Adapun normanya yaitu norma hukum yang berifat memaksa yang wajib ditaati dan dipatuhi, karena apabila norma hukum tersebut dilanggar maka diberikan sanksi.

Undang-Undang Dasar Negara Republik Indonesia Pasal 1 ayat (1) menyebutkan bahwanegara Indonesia adalah Negara hukum.Maka dengan ketentuan itu, salah satu prinsip Negara hokum yaitua dan yajaminan kesederajatan bagi setiap orang dihadapan hukum.

Tujuan pemidanaan didalam hokum pidana dikenal dengan adanya salah satu teori pembalasan. Teori pembalasan yaitu dimana menekan di unsur balas dendam d anefek jeraterhadap narapidana di Lembaga Pemasyarakatan.

Namun pembinaan di Lembaga Pemasyarakatan yang menekan di unsur balas dendam dan efekjera, dianggap tidak sejalan dengan konsep rehabilitasi dan reintegrasisosial yang dimana narapidana tersebut dapat diterima oleh masyarakat serta tidak lagi melakukan perbuatannya. Di dalam Lembaga Pemasyarakatan, Narapidana mempunyai hak yang diatur didalamUndang-Undang No. 12 Tahun 1995 seperti mendapat perawatan, mendapat pendidikan, dan lain-lain.

Pelaksanaan pemberian hak terhadap narapidana terlaksana dengan baik ataupun tidak dapa tterlaksana dengan baik, tanpa terkecuali juga terhadap narapidana pelaku tindak pidana pembunuhan di LembagaPemasyarakatanKlas II B Gunungsitoli, Nias.Oleh karena itu, berdasarkan uraian diatas, maka penulis melakukan penelitian dengan mengangkat judul " Pelaksanaan Pemberian HakHakNarapidanaPelakuTindakPidana Pembunuhan (Studi Di LembagaPemasyarakatanKlas II B Gunungsitoli, Nias)".

\section{B. Rumusan Masalah}

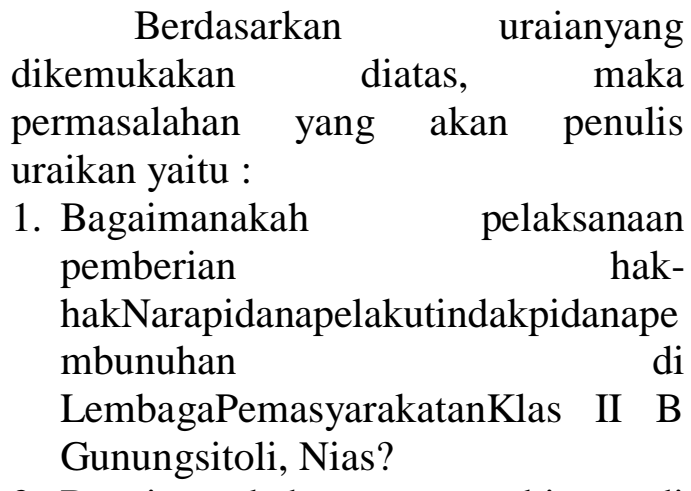

2. Bagaimanakah proses pembinaan di LembagaPemasyarakatanKlas II B Gunungsitoli,

Niasterhadapnarapidanatindakpidana pembunuhan?

\section{TINJAUAN PUSTAKA}

Adapun teori yang digunakan dalam pelaksanaan penelitian jurnal ini adalah teori negara hukum yaitunegara yang strukturnya diatur didalam undangundang sehingga semuak ekuasaan dari alat pemerintahan didasarkan padahukum.Rakyat dilarang untuk bertindak sendiriatau yang bertentangan dengan hukum. Negara hukum adalah sebuah negara yang diperintahkan bukan oleh orang-orang, akantetapi diperintahkan oleh undang-undang.Oleh karena itu, didalam sebuah Negara hukum, hak rakyat itu dijamins epenuhnya oleh Negara dan terhadap tersebut, sebaliknya rakyat tunduk dan taat kepada segala peraturan pemerintahan dan undang-undangnya.

\section{METODE PELAKSANAAN}

\section{A. Ruang Lingkup Penelitian}

Ruang lingkup jurnal iniyaitu untuk mengetahui bagaimanakah pelaksanaan pemberian hak-hak narapidana pelaku tindak pidana 
pembunuhan di Lembaga Pemasyarakatan Klas II B Gunungsitoli, Nias dan untuk mengetahui bagaimanakah proses pembinaan di Lembaga Pemasyarakatan Klas II B Gunungsitoli, Niasterhadapnarapidana yang

melakukantindakpidanapembunuhan.

\section{B. Jenis Penelitian}

Jenis penelitian ini adalah penelitian yuridis empiris.yaknipenelitian lapanganyang dilakukan dengancara wawancara.

\section{Metode Pendekatan Masalah}

Metode pendekatan masalah dilakukan dengan cara Pendekatan Perundang-

Undangan(StatuteApproach).

\section{Sumber Bahan Hukum}

Sumber bahan hukum adalah sebagai berikut :

1. Sumber hukum primer yaitu sumber hukum yang didapatdariobjek penelitian berupa observasi dan wawancara.

2. Sumber hukum sekunder yaitu sumber hukum yang diperoleh melalui study kepustakaan.

\section{E. MetodePengumpulan Data}

Metodepengumpulan data dalam penulisan jurnal ini dilakukan dengan cara :

1. Penelitian Lapangan (FieldResearch) Data atau informasi yang diperoleh langsung melalui wawancara atau pembicaraan langsung dan terbuka dalam bentuk tanya jawab terhadap narasumber.

2. Penelitian

Kepustakaan(LibrangResearch)

Data yang didapatdari kajian atau penelaahan berbagai sumber kepustakaan, dokumen, laporanlaporan.

\section{F. Metode Analisis Data}

Metode analisis data yang akandilakukansecara kumulatif yuridis.
Data primer yang didapat dari sebuahhasil penelitian disusun sedemikian rupa kemudian dianalisis secara deskriptif serta dikaitkan dengan data sekunder dengan menggunakan metode berpikir deduktif induktif yang berpedoman pada hukum pidana dan peraturan perundang - undangan yang berhubungan dengan permasalahan yang diteliti guna menjawab permasalahan.

\section{HASIL DAN PEMBAHASAN}

A. Pelaksanaan Pemberian HakHakNarapidanaPelakuTindakPidan aPembunuhan Di LembagaPemasyarakatanKlas II B Gunungsitoli, Nias

Berdasarkan hasil wawancara yang dilakukan penulis pada tanggal 14 Mei 2018 di Lembaga Pemasyarakatan Klas II B Gunungsitoli, Nias dengan Bapak Yunus M. Simangunsong selaku Kepala Lembaga Pemasyarakatan Klas II B Gunungsitoli, Nias beliau mengemukakan bahwa:

Pada pelaksanaan pemberian hakhak narapidana di Lembaga Pemasyarakatan Klas II B Gunungsitoli, Nias kami selaku petugas Lembaga Pemasyarakatan tidak membeda-bedakan atau mendiskriminasikan dalam memberikan hak-hak kepadanarapidana, semua narapidana mendapatkan hak sesuai dengan peraturan yang berlaku tanpa terkecuali.

Menurut Bapak Yunus M. Simangunsong, pelaksanaan pemberian hak-hak narapidana di Lembaga Pemasyarakatan Klas II B Gunungsitoli, Nias untuk narapidana khususnya pelaku tindak pidana pembunuhan berdasarkan pasal/perkara 338 KUHP, 339 KUHP, 340 KUHP, dan 354 KUHP yang berjumlah 41 orang dilaksanakan sesuai dengan Pasal 14 ayat (1) Undang-Undang Nomor 12 Tahun 1995 tentang Pemasyarakatan. Ada beberapa 
hak-hak narapidana pelaku tindak pidana pembunuhan yang sudah terpenuhi seperti tetap diberikan remisi, menerima asimilasi, pembebasan bersyarat, menerima kunjungan dari keluarga, mengikuti ibadah, olahraga, menerima informasi dari luar dan hakhak lainnya.

Sejalan dengan perkataan Bapak Yunus M. Simangunsong diatas, Bapak Yamansudi Harefa selaku Kepala Sub Bagian Tata Usaha, mengatakan kepada penulis, bahwa:

Pelaksanaan pemberian hak-hak narapidana pelaku tindak pidana pembunuhan tetap diberikan remisi, asimilasi dan cuti menjelang bebas dengan syarat narapidana tersebut, khususnya narapidana pelaku tindak pidana pembunuhan berkelakuan baik selama di dalam Lembaga Pemasyarakatan.

Selanjutnya, Bapak Yunus M. Simangunsong mengungkapkan bahwa:

Dalam pelaksanaan pemberian hak-hak narapidana pelaku tindak pidana pembunuhan di Lembaga Pemasyarakatan Klas II B Gunungsitoli ada hambatan atau kendala yang timbul, yaitu perilaku yang berasal dari diri narapidana itu sendiri. Perilaku narapidana itu seperti terlibat atau melakukan tindakan indisipliner, contohnya melanggar peraturan Lembaga Pemasyarakatan Klas II B Gunungsitoli, Nias atau melawan petugas.

Untuk mengatasi hambatan atau kendala dalam pelaksanaan pemberian hak-hak narapidana pelaku tindak pidana pembunuhan tersebut, Bapak Yunus $\mathrm{M}$. Simangunsong mengatakan bahwa:

Lembaga Pemasyarakatan Klas II B Gunungsitoli, Nias melakukan upaya dengan cara pelaksanakan pembinaan di
Lembaga Pemasyarakatan lebih dioptimalkan melalui pembinaan yang terstruktur dan berkesinambungan agar narapidana menyadari kesalahannya dan tidak akan mengulangi lagi kesalahan tersebut.

\section{B. Proses Pembinaan Di Lembaga Pemasyarakatan Terhadap Narapidana Yang Melakukan Tindak Pidana Pembunuhan Di Lembaga Pemasyarakatan Kelas II B Gunungsitoli, Nias}

Berdasarkan hasil wawancara yang dilakukan penulis pada tanggal 14 Mei 2018 di Lembaga Pemasyarakatan Klas II B Gunungsitoli, Nias dengan Bapak Yosua Zebua selaku Kepala Seksi Bimbingan Narapidana/Anak Didik dan Kegiatan Kerja, beliau mengemukakan bahwa:

Proses pembinaan di Lembaga Pemasyarakatan Klas II B Gunungsitoli, Nias terhadap narapidana yang melakukan tindak pidana pembunuhan, yaitu dimulai pada saat narapidana tersebut dititipkan di Lembaga Pemasyarakatan Klas II B Gunungsitoli. Proses pembinaannya dilaksanakan melalui kegiatan kerohanian, olahraga, pembinaan keterampilan, pemberian remisi, pemberian asimilasi, cuti menjelang bebas, dan pembebasan bersyarat.

Beliau juga mengatakan bahwa dalam proses pembinaan, ada beberapa tahap-tahap pembinaan yang dilakukan oleh Lembaga Pemasyarakatan Klas II B Gunungsitoli, Nias yaitu:

1. Tahap Awal

2. Tahap Lanjutan

3. Tahap Akhir

Bapak Yosua Zebua juga menuturkan bahwa di Lembaga Pemasyarakatan Klas II B Gunungsitoli, 
Nias ada beberapa bentuk-bentuk pembinaan yaitu:

1. Pembinaan Kepribadian

2. Pembinaan Kemandirian.

3.

5. SIMPULAN

A. Kesimpulan

Berdasarkan penelitian yang dilakukan oleh penulis mengenai Pelaksanaan Pemberian Hak-Hak Narapidana Pelaku Tindak Pidana Pembunuhan Di Lembaga Pemasyarakatan Klas II B Gunungsitoli, Nias. Penulis menyimpulkan bahwa:

1. Pelaksanaan Pemberian Hak-Hak Narapidana Pelaku Tindak Pidana Pembunuhan Di Lembaga Pemasyarakatan Klas II B Gunungsitoli, Nias telah dilaksanakan sesuai dengan Pasal 14 ayat (1) Undang-Undang Nomor 12 Tahun 1995 tentang Pemasyarakatan, antara lain tetap diberikan remisi, menerima asimilasi, pembebasan bersyarat, cuti menjelang bebas, menerima kunjungan dari keluarga, mengikuti ibadah, olahraga, menerima informasi dari luar dan hak-hak lainnya.

2. Proses Pembinaan Di Lembaga Pemasyarakatan Terhadap Narapidana Pelaku Tindak Pidana Pembunuhan Di Lembaga Pemasyarakatan Klas II B Gunungsitoli, Nias yaitu dimulai pada saat narapidana tersebut ditahan di Kepolisian yang selanjutnya di Rutan Gunungsitoli pada tahap sedang menjalani persidangan dan di lanjutkan di Lembaga Pemasyarakatan Klas II B Gunungsitoli, Nias sampai narapidana tersebut bebas.

\section{B. Saran}

Setelah melakukan penelitian terhadap Pelaksanaan Pemberian HakHak Narapidana Pelaku Tindak Pidana Pembunuhan Di Lembaga
Pemasyarakatan Klas II B Gunungsitoli, Nias dan memperhatikan data-data yang penulis peroleh, maka penulis mencoba memberikan saran-saran sebagai bahan evaluasi, yaitu

1. Agar kiranya Lembaga Pemasyarakatan Klas II B Gunungsitoli, Nias lebih mengoptimalkan dan menindak keras Narapidana khususnya pelaku tindak pidana pembunuhan yang melakukan tindakan indisipliner agar pelaksanaan hak-hak narapidana berjalan dan terlaksana dengan baik.

2. Agar kiranya Lembaga Pemasyarakatan Klas II B Gunungsitoli, Nias memperhatikan fasilitas sarana dan prasarana di Lembaga Pemasyarakatan Klas II B Gunungsitoli, Nias yang masih belum memadai dengan cara memberitahukan kepada Kanwil Sumatera Utara.

\section{DAFTAR PUSTAKA}

\section{A. BUKU}

Fadjar, Abdul Mukthie. 2016.Sejarah, Elemen dan Tipe Negara Hukum, Malang: Setara

Press

\author{
B. UNDANG-UNDANG \\ Undang-Undang Nomor 12 Tahun \\ KitabUndang-UndangHukumPidana
} 1995 